\title{
Big-Data and Consumer Profiles - The hidden traps of data collection on social media networks
}

\author{
Corina PELAU \\ Bucharest University of Economic Studies, Romania \\ corina.pelau@fabiz.ase.ro \\ Mihaela STANESCU \\ Bucharest University of Economic Studies, Romania \\ mihaela.stanescu@mediainvestment.ro \\ Daniela SERBAN \\ Bucharest University of Economic Studies, Romania \\ danielaserban2011@gmail.com
}

\begin{abstract}
The development and increased popularity of the social media networks has changed the way consumers communicate and interact with each other. But besides the positive aspects regarding socializing, real-time communication and information sharing, the social media networks have also several disadvantages. Private data security, invasion of privacy, misuse of information are just some of the negative aspects associated to social media networks, of which many of the consumers are not aware. This paper gives an overview of the different methods in which private consumer data and consumer profiles are created with the help of social media networks. The paper focuses on three main components, namely the data provided by the consumers, the technologies that have the ability to collect data in an aware or unaware manner and the contribution and advantages of business in this process. The results show that some of the data are given by the consumer, while other are just gathered with the help of automated and intelligent systems or applications.
\end{abstract}

Keywords: data protection, big data, consumers, social media networks, cookies, social sharing.

\section{Introduction}

The development of the internet and especially the social media networks has changed the way people communicate. They are nowadays one of the most active means of communication, by giving the possibility to share information with larger groups of people. The development of social media has come with several advantages such as easier way of communication by developing a real-time spread of information, intensive socializing by extending the social network as well as possibilities of business development through brand development, sharing of knowledge (Nisar, et al., 2019) and even a potential for innovation (Muninger, et al. 2019). Especially for young people the use of social media networks is interesting and they spend a big part of their time connected to it (Pelau \& Ene, 2018).

Besides the positive aspects that social media have triggered, there are also several disadvantages, when using social media networks. Several authors agree on the fact that the use of social media networks exposes the users to several risks (Haynes, et al., 2016; Vatamanescu et al., 2017). Among the disadvantages of social media networks there are the protection of personal data on social media networks, manipulation of consumers by 
targeted communication and spreading of fake news (Tantau et al., 2018), cyberbullying or the addictive use (Baccarella, et al.; 2018).

One of the most debated discussion related to the use of social media networks is about the use and exposure of private data of consumers in the online environment. In this article, we give an overview of the different ways in which consumer data is collected on the internet.

\section{Literature review}

With the development of the internet and the social media networks, several consumer data can be collected and stored with the help of automated and intelligent systems. These phenomenon of data collection is known as big data (Ghani et al., 2018). Besides the discussion on the security and privacy of the data, there is still a challenge for researchers and practitioners in the analysis of these big amounts of data (Ghani et al., 2018). Much of the analysis is done with the help of the automated systems, based on algorithms and preprogrammed procedures. In spite of this, there is still the need of a human mind (Pop \& Pelau, 2017) in order to prioritize the data and set some objectives.

Another discussion related to big data collected with the help of the internet and social media networks is the security of the data. The fascination of social media networks has determined consumer to post several private information and pictures in the online environment, without thinking too much to the risks involved with their exposure. With the development of the business orientation and presence on social media, the need increased for a certain regulation in exposing data in the online environment. According to Lessig (2006) there are four ways of regulation for data protection and data content on the internet: law, norms or self-regulation, architecture of system in which the data is introduced and markets. The law is one of the instruments that can limit the privacy regulations on the internet. Despite this, if the consumer is willing to post his/her private information on the internet it is difficult to limit the flow of data. For this reason self-regulation is important when talking about posting data on social media platforms. Not less important is the system architecture that allows the tracking of the consumer behavior in the online environment as well as the different companies, which use the data for profit purposes.

\section{Methodology}

The objective of the research is to give an overview of the possible means of data collection by social media networks, based on secondary research data. The aim of the paper has been to identify and categorize the different typology of data collection means with the help of social media networks. In order to obtain the results we have made a brainstorming of all types of possible user data collection on the internet. For each identified mean, we have tried to identify the main driver/ responsible. Based on the results, we have developed the results presented in the following.

\section{Results and discussion}

The result of our analysis shows that there are several methods of collecting consumer data from the internet, with the help of social media networks. Starting from the models analyzed before, the methods of collecting data, can be divided into three categories, driven by the 
consumers, by the technology or by the businesses, which uses the data for marketing purposes. The data collected from the consumer can be divided into two sub-categories: the data of which the consumer is aware that he/she introduces it into the system and the one of which he/she is not aware of giving it to the system. The data collection based on the technological ability of the system is also done in two ways: with permission from the consumer and with restricted permission (when the consumer is not aware of the fact that he/she lets the system store certain information. The business driven data collection occurs again in two ways: by automatic analysis of the data or by targeted analysis of the employees of the company. These categories and examples for each of them can be observed in table 1.

Table 1. Methods of data collection on Social Media Networks

\begin{tabular}{|c|c|c|}
\hline Category & Type & Examples \\
\hline \multirow[t]{2}{*}{$\begin{array}{l}\text { Consumer } \\
\text { driven }\end{array}$} & Aware of giving the data & $\begin{array}{l}\text { Introduction of personal data on Social Networks } \\
\text { Introduction of interest on Social Networks }\end{array}$ \\
\hline & Unaware of giving data & $\begin{array}{l}\text { Downloading of mobile application with access to } \\
\text { laptop/ mobile phone data }\end{array}$ \\
\hline \multirow[t]{2}{*}{$\begin{array}{l}\text { Technology } \\
\text { driven }\end{array}$} & $\begin{array}{l}\text { Information with } \\
\text { permitted access }\end{array}$ & $\begin{array}{l}\text { Cookies politics } \\
\text { Advertising settings (permission to re-market } \\
\text { advertisings with which the consumer has } \\
\text { interacted) }\end{array}$ \\
\hline & $\begin{array}{l}\text { Information without } \\
\text { permitted access }\end{array}$ & $\begin{array}{l}\text { Consumer profiles based on browsing and search } \\
\text { history } \\
\text { Active Location for mobile devices }\end{array}$ \\
\hline \multirow[t]{2}{*}{$\begin{array}{l}\text { Business } \\
\text { driven }\end{array}$} & $\begin{array}{l}\text { Data analysis by third } \\
\text { parties humans }\end{array}$ & $\begin{array}{l}\text { Targeted advertising based on social media platform } \\
\text { profiles }\end{array}$ \\
\hline & $\begin{array}{l}\text { Data analysis by third } \\
\text { parties machines/ } \\
\text { artificial intelligence }\end{array}$ & $\begin{array}{l}\text { Recommender/ Recommendation systems (Amazon } \\
\text { for instance) }\end{array}$ \\
\hline
\end{tabular}

\section{Consumer driven data collection}

The simplest way of collecting data is the one provided by the consumer himself/herself. On social media networks, the basic demographic data is provided to the system when creating an account. For creating a social media account, it is compulsory for the user to provide the name, surname, email, telephone, gender, age and another valid mail address in case of password recovery. Only by providing these (or similar) information, the account will be valid and functional. Additional to these data, the user can also introduce information regarding education (high-school, university), workplace, location/region, social status (married/ single/ engaged) and interests as movie, music, politics, shows, actors etc. Introducing the personal information has advantages and disadvantages for both the user and the social media platform. On one hand the social network user has a vast profile that can help him/her to appear in the searches of people with whom, he shares similarities in terms of profile (high-school, university, and workplace). On the other hand the social network can develop targeted advertising campaign by clustering the profiles registered based on different interests. The disadvantages of the introduction of data lies in the exposure of 
private information to the public and a risk exists, that the personal data of a user can be misused.

Besides the introduction of personal data, there is also the possibility to provide personal data, without being aware of it. Most of the mobile applications require many permissions to the smartphone-user, as for instance location, camera, SMS, microphone, contacts, calendar and other. In the moment of the download, the user is asked if he allows the permissions required by the application, but many users don't really read carefully all the PICBE | permissions they have to grant, because of bounded knowledge (Estrada-Jimenez et al, 2017). Therefore, the download of the application represents the user acceptance for the application to record and store several personal data from the consumer. Because of the lack of control, bounded technical knowledge (Estrada-Jimenez et al. 2017) or just because of the rush of downloading certain applications, most of the time, the consumer is unaware of the fact that he allowed the application to access his/her personal data and few users check their application permissions based on the procedure described in figure 1. At a more attentive look, most of the applications have access to the contacts and location of the user. Periodical changes of privacy settings on social media networks is another way in which consumer data is collected, without being aware of it (Haynes et al. 2016).

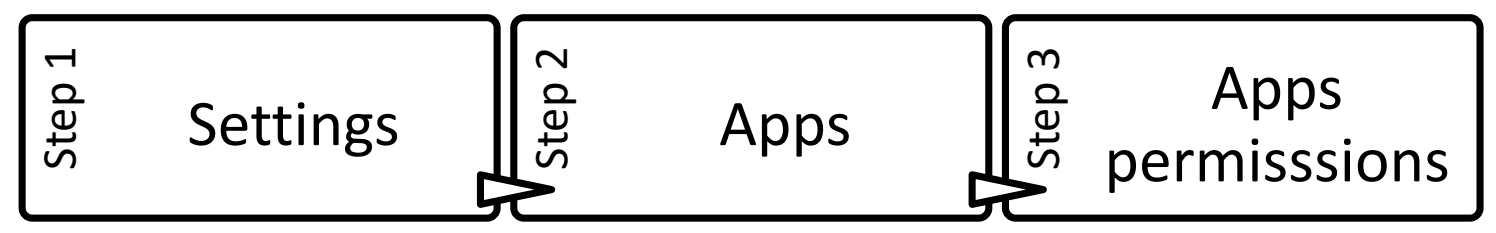

\section{Figure 1. Procedure to check application permissions on mobile phones for Android version 8.0.0}

Technology driven data collection

Source: Authors' own design.

Besides the personal data provided in an aware or unaware way, there have been developed several technologies that track the online behavior of the consumers. One of the best ways to store browsing data of users is done with the help of cookies. A "cookie" is a small amount of data that is sent to a user browser from a web server and stored on all devices (computer, tablet or smartphone), to help websites remember who the user is and as many information about his visit (European Commissions, 2019). The cookies are used for two main purposes. On one hand to provide the user with a better and more personalized experience. On the other hand with the help of cookies, consumer profiles can be developed, which can afterwards be used in advertising (Sanchez \& Viejo, 2018; Yue, et al. 2010). There are three different categories of cookies. Based on the time the cookie is stored there are according to the European Commission (2019) session and persistent cookies. Based on the "owner" of the cookie, there are first party or third party cookies (European Commission, 2019).

The session cookies allow the consumers to use the site in the way he wishes, by improving the convenience and the efficiency of the website, but they are erased once the browser is closed (European Commission, 2019). The persistent cookies are used to help the website to understand and describe the behavior of the consumer. These cookies tell the 
website how often a consumer visits the site and how he is using it (what pages he/she opens, time spend per page or per site, bounce rate etc.) (Sanchez \& Viejo, 2018). These kind of information are also important for the website in order to improve its performance.

The third party cookies are the one stored on a user device by other parties (EstradaJimenez, et al, 2017). They are used with the purpose of having a third party to provide the website with a service or enable some functionality on the site (Sanchez \& Viejo, 2018). These type of cookies occur frequently with the help of social sharing. For instance all important PICBE | internet platforms have a possibility of social sharing. Facebook has the "Like" button (Facebook for developers (2019c), while Twitter has the "tweet" button (Twitter developer, 2019). By expressing a certain positive feeling about an idea, automatically the platform records the preference of the consumer and stores it to his/her profile.

The major revenue source for the websites and internet companies is represented by the advertising space, they are selling (Statista, 2019). As most social media networks are free for users, their main incomes come from the selling of the user profiles collected from the users (Haynes et al. 2016). In order to make the website more relevant and interesting for the user in terms of the advertising that is exposing, the website is interested to know more about the user and the things that he is interested in. Based on cookies information, the website can expose ads according to the user profile (interest-based-advertising). This has benefit for both sides. The website can demand a higher cost for exposure from the advertiser and the user benefit from relevant content based on its profile. (Estrada-Jimenez et al., 2017).

The new GDPR law has set rules for the storing of cookies. According to GDPR, all the websites have to ask for the users' permission of storing cookies by exposing a box with "Accept" or "OK". This procedure has made internet browsing more difficult as any opened site asks the permission of users to store cookies. Besides, there is still a discussion if the users have enough information about the types of cookies they should allow (EstradaJimenez et al., 2017).

Besides the information, where the user gives access to the platform, there are also other methods of storing user data such as browsing and search history, and partially the location finder. Most websites that the user visited will place a cookie in his browser, which is a piece of information that the browser can use to "remember" certain states (EstradaJimenez et al., 2017). For example, a cookie can remember that the user already logged into a website, so next time you turn on your computer and visit that site, you won't have to log in again. If you delete all of your cookies while cleaning out the private data in your browser, the website will immediately ask you to log in again. Search history is another information that is stored by the website and it is frequently used in order to give performance data of websites. The access to the stored information in the user browser can allow different platforms to target ads by examining these cookies from the user browser (Estrada-Jimenez, et al., 2017).

Another interesting information about the consumers is the location and the space in which he/she does his/her activity. Different sites and applications try to access the location of the consumers by different means. One way of collecting the location of the consumer is through the different GPS systems or maps applications, such as Google Maps (The Guardian, 2018). Of course the consumer has certain facilities of finding much easier the way or by obtaining traffic information, but the applications stores the routes and locations of the consumer. In some platforms that provide mail activity, the user can see inside his own 
account the history, composed from all the posts that he liked or shared, what did he search for and when. This information is very useful for the platforms in terms of advertising, as personalized ads can be displayed based on a specific interest (Jung, 2017).

\section{Business driven data collection}

Most of the data about the consumers' profiles is used in order to increase the efficiency of business processes. The analysis of the data collected from the internet is done both by humans, by machines or by a combination of the two. Taking into consideration the fact that the amount of the collected data has increased with the development of intelligent system, its analysis is done more and more in an automated manner with the help of intelligent systems (Ene, 2018). The humans continue to have an important role in programming the machines, but most of the analysis is done by intelligent systems.

Advertising is one of the main fields in which the consumer data is important for correctly targeting the communication. The data collected from the internet sites is used in order to profile the consumers based on their behavior and interest. For instance people who upload on social media pictures with children, receive information and advertising for children products. The information uploaded on different online media is transformed into targeting segments, as it can be seen in table 2 .

\section{Figure 2. User information and consumer profiles}

\begin{tabular}{c|c}
\hline Information provided by user & Information analyzed by advertiser \\
\hline 30 years & Between 18-35 years \\
\hline Female & Female \\
\hline Bucharest Center & Within 5 km from my store \\
\hline $\begin{array}{c}\text { Interested in: travel, cycling, cooking, } \\
\text { fashion shopper }\end{array}$ & Interested in travel \\
\hline Smart-phone user, & Mobile user \\
\hline
\end{tabular}

Some social media networks already allow business to target their consumer segments with the help of the online collected consumer-data. For instance, Facebook Core Audiences helps businesses to select the right recipients for your ad in just a few clicks (Facebook Business, 2014a). Companies can target their consumers based on age, location, hobbies, behavior or social connections (Facebook Business, 2014a). Facebook Custom Audiences gives the business the possibility to access consumers who have already shown interest in your business. It allows companies to compare their customer data and match is with social media profiles based on phone numbers or e-mail addresses. By this, companies can contact and communicate with their customers through the social media network (Facebook Business, 2019a). It also allows to install a pixel on the website with the purpose of creating an audience of consumers who have visited it. Moreover, it can also show the things for which the consumer has shown interest (Facebook for developers, 2019a). The same service is also offered for mobile applications, so that companies can track their consumers via their mobile phone and the interest shown by using it (Facebook for developers, 2019a). Another service offered is the Facebook Lookalike Audiences. This 
service allow companies to target users which have similar profiles as those of their customers (Facebook Business, 2019b). Besides these targeting services, Facebook also provides Audience Insights, a tool that aggregates attributes, characteristics and behaviours of consumers in order to better define the own customers (Facebook Business, 2014b).

The process of data analysis is more frequently done by automated systems. Based on predefined programmers and algorithms certain advertising recommendations are posted on the website of consumers, based on previous behavior. The recommendation system is based on machine learning, by using artificial intelligence systems for the processing of data. The learning process of the artificial intelligence is done by the imitation of human neural networks and providing information as a pattern (Zihayat et al., 2019).

\section{Conclusion}

In the past years the development of applications and automated systems on the internet have influenced in a positive and convenient way the life of consumers, by increasing the efficiency of several activities. The consumer has to no longer the responsibility of memorizing certain information as the surrounding devices, such as laptop, tablet or mobilephone do it for him and with the development of the internet of things, this trend will go on. But, there is also a reversed side of this convenience, namely the fact that all these devices store information about the behaviour and the habits of the consumer. With the help of intelligent systems, theses information can be used for several purposes such as advertising and targeting or even the manipulation of the consumer. The more we, as consumers, rely on the information and recommendation of the intelligent devices, the more will our behavior be influenced by the procedures pre-defined in these systems.

Based on these technological developments several research question arise for the future. The first question is about the relation to the intelligent systems. Are these systems our friends by improving our life or are they rather a foe who store our information with the purpose of influencing our behavior. No one can contest the fact that several technological developments have improved our life by making it much easier to communicate or by recommending different actions. Certain actions that have been done manually in the past are now, being done by different devices or applications. But, there is also a reversed side. In order to have efficient procedures and user-friendly applications, these systems have to store our data. So, the second question which arises is if the private information which we provide to these systems is the price for our convenience. To rephrase this idea: how much are we, as consumers willing to pay in order to have access to efficient and user-friendly systems and applications. Therefore in order to both protect the private data and contribute to the development of science and user-friendly applications, it is important to find an equilibrium between the data provided to these systems. The GDPR law is a first step for this equilibrium, but with the development of new technologies, new methods of saving private data will be probably developed in the future.

\section{References}

Baccarella, C.V.; Wagner, T.F.; Kietzmann, J.H.; McCarthy, I.P. (2018). Social media? It's serious! Understanding the dark side of social media, European Management Journal, 36, 431-438. 
Ene. I. (2018). Study of Consumer's Unconscious Reaction towards the Use of Anthropomorphic Appearance of AI: An Eye-tracking Experiment, Studia Universitatis Vasile Goldis, 28(4), 55-67.

Estrada-Jimenez, J.; Parra-Arnau, J.; Rodríguez-Hoyos, A.; Fornec, J. (2017). Online advertising: Analysis of privacy threats and protection approaches, Computer Communications, 100, 32-51, http://dx.doi.org/10.1016/j.comcom.2016.12.016.

European Commission (2019). The EU Internet Handbook - Cookies, 1077 http://ec.europa.eu/ipg/basics/legal/cookies/index_en.htm, (accessed: 27.01.2019).

Facebook Business (2019a). Target Facebook Ads to people on your contact list, https://www.facebook.com/business/a/custom-audiences (accessed: 27.01.2019).

Facebook Business (2019b). Despre audiențele asemănătoare, https://www.facebook.com/business/help/164749007013531 (accessed: 27.01.2019).

Facebook for developers (2019a). Facebook Pixel, https://developers.facebook.com/docs/facebook-pixel/ (accessed: 27.01.2019).

Facebook for developers (2019b). Facebook SDK for iOS - Build engaging social apps and get more installs, https://developers.facebook.com/docs/ios/ (accessed: 27.01.2019).

Facebook for developers (2019c). Like Button for the Web, https://developers.facebook.com/docs/plugins/like-button/ (accessed: 27.01.2019)

Facebook Business (2014a). Easier, More Effective Ways to Reach the Right People on Facebook, https://www.facebook.com/business/news/Core-Audiences (accessed: 27.01.2019).

Facebook Business (2014b). Learn More About the People that Matter to Your Business with Facebook Audience Insights, https://www.facebook.com/business/news/audienceinsights (accessed: 27.01.2019).

Ghani, N.A.; Hamid, S.; Hashem, I.A.T.; Ahmed, E. (2018). Social media big data analytics: A survey, Computers in Human Behavior, In Press, available: https://doi.org/10.1016/j.chb.2018.08.039.

Haynes, D.; Bawden, D.; Robinson, L. (2016). A regulatory model for personal data on social networking services in the UK, International Journal of Information Management, 36, 872-882, http://dx.doi.org/10.1016/j.ijinfomgt.2016.05.012.

Jung, A.R. (2017). The influence of perceived ad relevance on social media advertising: An empirical examination of a mediating role of privacy concern, Computers in Human Behavior, 70, 303-309.

Muninger, M.I.; Hammedi, W.; Mahr, D. (2019). The value of social media for innovation: A capability perspective, Journal of Business Research, 95, 116-127.

Nisar T.M.; Prabhakar, G.; Strakova, L. (2019). Social media information benefits, knowledge management and smart organizations, Journal of Business Research, 94, 264-272.

Pelau, C.; Ene, I. (2018). Consumers' perception on human-like artificial intelligence devices, Fourth BASIQ International Conference on New Trends in Sustainable Business and Consumption (BASIQ), Heidelberg, Germany, 197-203.

Lessig, L. (2006). Code (2nd ed.). New York; London: BasicBooks.

Pop, N.Al. (2018), Quo Vadis Romanian Marketing: The Future and Contribution of the Romanian Community, in: Vaduva S.; Wilt, R.; Fotea, I.; Vaduva L.P. (2018): Civil Society: The Engine for Economic and Social Well-Being, Springer. 
Pop, N.Al.; Pelau, C. (2017). Correlations within the EFQM Business Excellence Model by Applying a Factor Analysis, Amfiteatru Economic, 19(44), 28-40.

Sanchez, D.; Viejo, A. (2018). Privacy-preserving and advertising-friendly web surfing, Computer Communications, 130, 113-123.

Statista (2019). Advertising revenues of selected social networks in the United States from 2015 to 2018 (in million U.S. dollars), https://www.statista.com/statistics/426520/ussocial-networks-ad-revenues/ (accessed: 27.01.2019).

Susanu, C. (2017). Ce stie facebook despre tine?, https://www.cipriansusanu.ro/blog/ce-stiefacebook-despre-tine/ (12.01.2019).

Tanțău, A.; Pelau, C.; Pop, M. (2018). Fake news in the energy industry, Fourth BASIQ International Conference on New Trends in Sustainable Business and Consumption (BASIQ), 204-210.

The Guardian (2018). Google records your location even when you tell it not to, https://www.theguardian.com/technology/2018/aug/13/google-location-trackingandroid-iphone-mobile, (accessed: 27.01.2019).

Twitter developer (2019). Tweet Button, https://developer.twitter.com/en/docs/twitterfor-websites/tweet-button/overview.html (accessed: 27.01.2019).

Vatamanescu, E.M.; Nistoreanu, B.G.; Mitan, A. (2017). Competition and Consumer Behavior in the Context of the Digital Economy, Amfiteatru Economic, 19(45), 354-366.

Yue, C.; Xie, M.; Wang, H. (2010). An automatic HTTP cookie management system, Computer Networks, 54(13) 2182-2198.

Zihayat, M.; Ayanso, A.; Zhao, X.; Davoudic, H.; An, A. (2019). A utility-based news recommendation system, Decision Support Systems, 117, 14-27. 